\title{
Physical activity of disabled individuals in the context of meeting WHO recommendations and support of local authorities
}

\author{
Elżbieta Biernat, ${ }^{1}$ Monika Piatkowska ${ }^{2}$ \\ ${ }^{1}$ Warsaw School of Economics, Warsaw, Poland \\ ${ }^{2}$ Josef Pilsudski University of Physical Education, Warsaw, Poland \\ Received: January 2016 Accepted: April 2016
}

\begin{abstract}
Objectives: This study aims to evaluate physical activity of disabled individuals in the context of fulfilling the World Health Organization (WHO) recommendations and to investigate the relationship between the risk of inactivity and activity of local authorities in this field.

Material and methods: The sample consisted of 155 disabled individuals selected from a representative sample of the Polish society. The long version of the International Physical Activity Questionnaire (IPAQ-LF) and the survey of the determinants of a sport activity among the Polish population were applied. The relationship between meeting the WHO recommendations and environmental factors were investigated.

Results: According to the IPAQ-LF, $68.2 \%$ of the Polish disabled adults performed a recommended dose of physical activity during their leisure time. The total leisure activity was composed mainly of vigorous activities (58.8\%), in a less extent of moderate activities (11.8\%), and walking (7.2\%). According to the survey of the sport activity determinants, $10.3 \%$ is active $(0.7 \%$ exercises for $\geq 60$ min 3 to 4 times a week, $3.9 \%$ per day).

Conclusion: Based on our study results, there is a need to increase the activity of local authorities, promoting a participation in sport for all among Polish disabled individuals. In addition, these study results indicate methodological problems related with the implementation of the IPAQ-LF.

Keywords: Disability; International Physical Activity Questionnaire-long version; leisure physical activity; Poland; World Health Organization recommendations.
\end{abstract}

In Poland, disabled individuals are those whose physical, psychological, or mental fitness permanently or temporarily hinder, impede, or preclude daily life activities, education, work, or serving social roles in accordance with the legal or customary norms. ${ }^{[1]}$ It is estimated that the number of disabled individuals in Poland ranges from 3.4 to about 4.7 million, ${ }^{[2]}$ accounting for 10.8 to $12.2 \%$ of the population of Poland. ${ }^{[3]}$ However, the population is constantly growing due to the increasing age, increasing levels of obesity, improved identification of various dysfunctions, and higher efficiency in both life rescue and life support. In 2002, the share of individuals with a severe level of disability was $21.1 \%$ including those with a moderate disability, $35.1 \%$, and those with a mild disability,
$42.7 \%{ }^{[2]}$ In 2012 , these rates were $28.3 \%, 40.9 \%$, and $30.8 \%$, respectively. ${ }^{[2]}$

The issue of the prevalence of disabilities is a substantial challenge for the Polish state. Providing disabled individuals favorable conditions for living, development, education, work, access to culture, and leisure is inherently related with the support of their health and proper level of physical fitness including cardiovascular and respiratory stability, stamina, flexibility, and balance. Currently, it is widely known that a regular physical activity is beneficial. Physical activity undertaken as a form of recreational exercise with suitably chosen intensity, duration and frequency can provide numerous health benefits, both preventive and therapeutic ones. It can also contribute 
to increasing capacity and efficiency of the physical resistance, as well as improving the overall wellbeing. It may, therefore, support work of physical therapists. It is obvious that greater difficulties of disabled individuals in performing their basic daily activities result in a higher rate of physical requirements. ${ }^{[4]}$ This is why it is alarming that, despite unquestionable advantages for health through regular physical activity, ${ }^{[5]}$ disabled individuals report insufficient physical activity more often than those without any disability. ${ }^{[5,6]}$

The majority of disabled individuals lack the World Health Organization (WHO) recommendations of 30 min physical activity daily five or more times a week. ${ }^{[7]}$ This low level of physical activity is a substantially greater problem than in healthy individuals who prefer sedentary lifestyle. Disabled individuals are - but not necessarily ${ }^{[4]}$ - vulnerable to functional limitations - related with their disabilities - (i.e., focal spasticity, autonomic dysfunction, urinary incontinence, convulsions, balance, or thermoregulation abnormalities) and accompanying secondary health problems (i.e., aches, fatigue, depression, or body mass increase).$^{[8,9]}$ In combination with a low level of physical activity and omnipresent diseases of affluence such as obesity, peripheral artery disease, back illnesses, diabetes mellitus type 2 , and asthma, these disabilities create real threats for their independence, their ability to work productively, and their participation in the private and social life. ${ }^{[8]}$

Therefore, it is not surprising that disabled individuals have worse health than healthy individuals. $^{[10,11]}$ However, health problems in these individuals do not directly result from the disability. ${ }^{[12,13]}$ They occur directly or indirectly as a result of a lack of pro-health behavior, ${ }^{[14,15]}$ such as due to smoking, a lack of physical activity, or obesity, ${ }^{[16]}$ as reported in an United States (US) study ${ }^{[17]} \mathrm{A}$ total of $30.5 \%$ of disabled individuals in the US are smokers, $31.2 \%$ are obese, and $22.4 \%$ are physically inactive, while these rates are mostly lower and $21.7 \%, 19.6 \%$, and $11.9 \%$, respectively in those without a disability.

This problem is also present among children and young individuals. ${ }^{[18,19]} \mathrm{A}$ comparison of risky behavior among young Canadians indicated that a lack of physical activity was observed 4.5 times more often in young disabled individuals than young individuals without disabilities. ${ }^{[20]}$ More interestingly, they watched TV for more than four hours a day two times as much. According to the Youth Risk Behavior Survey, the rate of schoolchildren who played video/computer games (more than three hours a day) was significantly higher among those with disabilities (26.6\%) than those without (20.4\%). The rate of those who were a member of a sport team was also significantly lower in disabled participants. ${ }^{[21]}$

Several authors suggest that such barriers for regular physical activity may result in further avoiding it, and as a result, sedentary time after school and during weekends may increase. ${ }^{[22]}$ In turn, a lower level of physical activity during childhood and adolescence may influence the occurrence of obesity and other risk factors in the adulthood. ${ }^{[23-25]}$ What is worse, disabled individuals already face numerous adversities. ${ }^{[26-28]}$ On one hand, as in the overall population, this results from a lack of time and interests; however, the employment rate among disabled individuals is substantially lower than in the general population, which leaves them more time for active rest. ${ }^{[29]}$ On the other hand, there are additional barriers for this social group. ${ }^{[29,30]}$ A lack of sport and recreation facilities in their neighborhoods, a lack of belief which the existing facilities have a friendly environment, high costs of participation, insufficient engagement of local authorities, a lack of information, available equipment, available programs, equipment not commensurate to the abilities of disabled individuals, minimal space between training equipment, limited space to move around on a wheelchair, poor lighting, and noise. ${ }^{[31,32]}$ These are only some of the obstacles that efficiently limit undertaking exercises. Their influence is significant to such a level that the use of the potential of regular physical activity in a group of disabled individuals may be impossible. Therefore, some authors suggest that barriers faced by these individuals who wish to be physically active should be identified first, and strategies to overcome these obstacles should be developed. ${ }^{[9,33]}$

In the present study, we aimed to evaluate physical activity of disabled individuals in the context of fulfilling the WHO recommendations and to investigate the relationship between the risk of inactivity and activity of local authorities in this field. Therefore, we studied several factors including the dependence between the activity of local authorities (providing a sufficient number of facilities, organization of sport events, and promotion of physical activity among citizens) and the offer of local authorities, sport clubs and organizations (number of paid and free sport facilities, their condition, costs and attractiveness of activities) and the risk of not reaching a health-enhanced dose of physical activity. 


\section{MATERIAL AND METHODS}

The sample consisted of 155 Polish disabled individuals aged between 15 and 69 years selected from the representative sample of the Polish society $(n=1,765)$. They were chosen through the stratifiedquota sampling method with the demographic variables such as age, sex, education, and the place of residence. The quotas were established proportionally, based on the data that were made accessible to the researchers by the Central Statistical Office. Furthermore, to increase the representativeness of the sample, data weighting procedure of the variables listed above were used. The quotas were proportionally assessed based on the data provided by Central Statistical Office (the data sources: National Census of Population and Local Data Bank). The study protocol was approved by the Committee of Ethics in Science of Polish Academy of Sciences. A written informed consent was obtained from each patient. The study was conducted in accordance with the principles of the Declaration of Helsinki.

In accordance with the Article 3 of the Act of 27 August, 1997 $7^{[1]}$ on the Professional and Social Rehabilitation and the Employment of the Disabled Persons with severe disability were selected as the respondents $(\mathrm{n}=27)$ with an impaired organism fitness, incapable to work or capable to work only in the conditions of supported employment and requiring to serve social roles, a constant or long-term help of other individuals due to incapability of unaided existence. Moderate disability concerned individuals $(n=81)$ with an impaired organism fitness, incapable to work or capable to work only in the conditions of supported employment or requiring to serve social roles, temporal or partial help of other individuals. Those with mild disability were the respondents $(n=47)$ with an impaired organism fitness, causing a significant decrease of the capability to work compared to the capability of an individual with similar professional qualifications, who was fully mentally and physically fit, or having limitations in serving social roles, which can be compensated with an use of orthopedic means, support means, or technical means.

The study was conducted between October 2012 and November 2012 using the individual ComputerAssisted Telephone Interviews (CATI). The interviews were administered by trained and supervised surveyors, who formed the questions in a way that was equally easy for all participants to comprehend. The research tools in the current investigation were the survey on the determinants of a sport activity among the Polish population and the Polish long version of the International Physical Activity Questionnaire (IPAQ-LF). The survey contained questions about the frequency, duration, place, and the type of sport for all activities. The participants were also asked about the accessibility of sports facilities and classes. Additionally, they were asked to rate the attractiveness of these classes and to provide ratings of the work done by local authorities within sport and recreation. The IPAQ-LF provides information about physical activity in specific domains such as occupational, commuting, domestic chores, sports, and leisure and the duration of sitting time during weekdays and weekends. ${ }^{[34]}$ It produces repeatable data (the Spearman's clustered around 0.8) with comparable data from short and long forms. The median criterion validity was 0.30 , which is comparable to most other self-report validation studies. ${ }^{[35]}$

In our study, only the information on physical activity undertaken in leisure time within the last week prior to the start of the study was obtained. After performing a standardized calculation of the durations and the frequencies of declared physical activities (vigorous, moderate activities, and walking), ${ }^{[36]}$ and with the WHO recommendations on the amount of physical activity needed to maintain a good health taken into account, respondents were divided into two groups: those who did not follow the recommendations and those who followed the recommendations, i.e., who reported undertaking $\geq 150$ min of moderate physical activity or $\geq 75$ min of vigorous physical activity per week (or the equivalent combination of the moderate and vigorous physical activity reaching at least 600 metabolic equivalent of task (MET)-min/week. In turn, those undertaking participation in sport for all at least were classified as physically active, and those engaging in physical activity at least $60 \mathrm{~min}$ three to four times per week or every day were classified as highly active.

\section{Statistical analysis}

Statistical analysis was performed using the IBM SPSS version 21.0 software (IBM Corp., Armonk, NY, USA). As for descriptive statistics, the distribution as a frequency of individual values for variables was calculated. The difference between nominal variables (participation in leisure physical activity, sport for all, and disability level) was calculated using the chi-square test. The relationship between meeting WHO recommendations and environmental factors among disabled individuals was examined by means of log-linear analysis. The strength of the relationship between these variables was expressed in the odds ratios (OR) with $95 \%$ confidence interval. A $p$ value of $<0.05$ was considered statistically significant. 


\section{RESULTS}

Demographic characteristics of the respondents are shown in Table 1. Most of the respondents $(n=155)$, regardless the level of their disability (severe - 30.3\%, moderate - $52.3 \%$ or mild - $17.4 \%$ ), - performed a recommended dose of physical activity during their leisure time (Table 2). A total recreation activity over $600 \mathrm{MET}-\mathrm{min} /$ week (a combination of vigorous and moderate intensities and walking) was reported by

Table 1. Demographic characteristics of the respondents $(n=155)$

\begin{tabular}{|c|c|c|c|c|c|c|c|}
\hline \multirow[t]{3}{*}{ Factors } & \multicolumn{6}{|c|}{ Disability level } & \multirow[b]{3}{*}{$p$} \\
\hline & \multicolumn{2}{|c|}{ Light $(n=27)$} & \multicolumn{2}{|c|}{ Moderate $(n=81)$} & \multicolumn{2}{|c|}{ Severe $(n=47)$} & \\
\hline & $\mathrm{n}$ & $\%$ & $\mathrm{n}$ & $\%$ & $\mathrm{n}$ & $\%$ & \\
\hline Sex & & & & & & & 0.39 \\
\hline Men & 15 & 55.6 & 48 & 59.3 & 22 & 46.8 & \\
\hline Women & 12 & 44.4 & 33 & 40.7 & 25 & 53.2 & \\
\hline Age (year) & & & & & & & 0.28 \\
\hline 15-19 & 1 & 3.7 & - & - & - & - & \\
\hline $20-24$ & 2 & 7.4 & 2 & 2.5 & - & - & \\
\hline $25-29$ & 1 & 3.7 & 4 & 4.9 & - & - & \\
\hline $30-39$ & 5 & 18.5 & 14 & 17.3 & 7 & 14.9 & \\
\hline $40-49$ & 4 & 14.8 & 13 & 16.0 & 4 & 8.5 & \\
\hline $50-5$ & 8 & 29.6 & 26 & 32.1 & 19 & 40.4 & \\
\hline $60-69$ & 6 & 22.2 & 22 & 27.2 & 17 & 36.2 & \\
\hline Education & & & & & & & 0.62 \\
\hline Secondary & 16 & 59.3 & 42 & 51.9 & 20 & 42.6 & \\
\hline Higher & 2 & 7.4 & 11 & 13.6 & 6 & 12.8 & \\
\hline Place of residence & & & & & & & 0.09 \\
\hline Village & 4 & 14.8 & 5 & 18.5 & 11 & 23.4 & \\
\hline City up to 20,000 inhibitants & 4 & 14.8 & 12 & 14.8 & 11 & 23.4 & \\
\hline City with $21,000-50,000$ inhibitants & 10 & 37.0 & 15 & 18.5 & 8 & 17.0 & \\
\hline City with $51,000-100,000$ inhibitants & 5 & 18.5 & 21 & 25.9 & 4 & 8.5 & \\
\hline City with 101,000-200,000 inhibitants & 3 & 11.1 & 2 & 2.5 & 4 & 8.5 & \\
\hline City over 200,000 inhibitants & 1 & 3.7 & 16 & 19.8 & 9 & 19.1 & \\
\hline Average monthly gross income (per capita in household)* & & & & & & & 0.74 \\
\hline$<1,000$ PLN & 7 & 25.9 & 15 & 18.5 & 7 & 14.9 & \\
\hline $1,000-1,999$ PLN & 8 & 29.6 & 27 & 33.3 & 20 & 42.6 & \\
\hline 2,000-2,999 PLN & 7 & 25.9 & 21 & 25.9 & 5 & 10.6 & \\
\hline 3,000-3,999 PLN & 2 & 7.4 & 8 & 9.9 & 7 & 14.9 & \\
\hline
\end{tabular}

* The percentages for average monthly gross income (per capita in household) do not total 100 due to possible missing data and lack of responses. 1,000 PLN $=235.05$ EUR; PLN: Polish Zloty; The chi-square test was used.

Table 2. Fraction of respondents participating in leisure physical activities (vigorous, moderate, total) depending on the level of their disabilities and World Health Organization recommended health-enhanced dose of physical activity (estimated by the IPAQ-LF)

\begin{tabular}{|c|c|c|c|c|c|c|c|c|c|}
\hline \multirow[b]{3}{*}{ Leisure physical activity } & \multicolumn{9}{|c|}{ Disability level } \\
\hline & \multicolumn{2}{|c|}{ Mild } & \multicolumn{2}{|c|}{ Moderate } & \multicolumn{2}{|c|}{ Severe } & \multirow{2}{*}{$p$} & \multicolumn{2}{|c|}{ Total } \\
\hline & $\mathrm{n}$ & $\%$ & $\mathrm{n}$ & $\%$ & $\mathrm{n}$ & $\%$ & & $\mathrm{n}$ & $\%$ \\
\hline \multicolumn{10}{|l|}{ Vigorous physical activity } \\
\hline$<75 \mathrm{~min} /$ week (<600 MET-min/week) & 12 & 44.4 & 34 & 42.0 & 17 & 37.8 & \multirow{2}{*}{0.84} & $63^{*}$ & 41.2 \\
\hline$\geq 75 \mathrm{~min} /$ week $(\geq 600 \mathrm{MET}-\mathrm{min} /$ week $)$ & 15 & 55.6 & 47 & 58.0 & 28 & 62.2 & & 90 & 58.8 \\
\hline \multicolumn{10}{|l|}{ Moderate physical activity } \\
\hline$<150 \mathrm{~min} /$ week $(<600 \mathrm{MET}-\mathrm{min} /$ week $)$ & 24 & 88.9 & 68 & 85.0 & 43 & 93.5 & \multirow{2}{*}{0.36} & 135 & 88.2 \\
\hline$\geq 150 \mathrm{~min} /$ week $(\geq 600 \mathrm{MET}-\mathrm{min} /$ week & 3 & 11.1 & 12 & 15.0 & 3 & 6.5 & & 18 & 11.8 \\
\hline \multicolumn{10}{|l|}{ Walking } \\
\hline <150 min/week (<495 MET-min/week) & 25 & 92.6 & 74 & 92.5 & 43 & 93.5 & \multirow{2}{*}{0.98} & 142 & 92.8 \\
\hline$\geq 150 \mathrm{~min} /$ week $(\geq 495 \mathrm{MET}-\mathrm{min} /$ week & 2 & 7.4 & 6 & 7.5 & 3 & 6.5 & & 11 & 7.2 \\
\hline \multicolumn{10}{|l|}{ Total leisure activity } \\
\hline$<600 \mathrm{MET}-\mathrm{min} /$ week & 10 & 37.0 & 26 & 32.5 & 12 & 27.3 & 0.68 & 48 & 31.8 \\
\hline
\end{tabular}

IPAQ-LF: International Physical Activity Questionnaire, long form; MET: Metabolic equivalent of task; * The data do not total 155 due to responses "do not know/not sure”. 
Table 3. Fraction of respondents participating in sport for all (3-4 times a week, everyday) depending on the level of their disabilities and World Health Organization recommended pro-health dose of physical activity (estimated on the basis of a survey)

\begin{tabular}{|c|c|c|c|c|c|c|c|c|}
\hline \multirow[b]{3}{*}{ Sport for all } & \multicolumn{8}{|c|}{ Disability level } \\
\hline & \multicolumn{2}{|c|}{ Mild } & \multicolumn{2}{|c|}{ Moderate } & \multicolumn{2}{|c|}{ Severe } & \multicolumn{2}{|c|}{ Total } \\
\hline & $\mathrm{n}$ & $\%$ & $\mathrm{n}$ & $\%$ & $\mathrm{n}$ & $\%$ & $\mathrm{n}$ & $\%$ \\
\hline \multicolumn{9}{|c|}{ 3-4 times a week } \\
\hline $30-59 \mathrm{~min}$ & 1 & 3.7 & 5 & 6.2 & - & - & 6 & 3.9 \\
\hline$\geq 60 \mathrm{~min}$ & 1 & 3.7 & - & - & - & - & 1 & 0.7 \\
\hline \multicolumn{9}{|l|}{ Everyday } \\
\hline $30-59 \mathrm{~min}$ & 1 & 3.7 & 1 & 1.2 & 1 & 2.1 & 3 & 1.9 \\
\hline$\geq 60 \mathrm{~min}$ & - & - & 3 & 3.7 & 3 & 6.4 & 6 & 3.9 \\
\hline
\end{tabular}

$68.2 \%$ respondents. No significant differences in the level of disability was observed. However, the total leisure activity mainly comprised vigorous activities ( $\geq 75 \mathrm{~min} /$ week) in $58.8 \%$, followed by $11.8 \%$ with moderate activity $(\geq 150 \mathrm{~min} /$ week $)$ and $7.2 \%$ with walking.

On the other hand, an analysis of the participation in sport for all) revealed that only a low number of participants (10.3\%) was physically active (Table 3 ). In addition, only $0.7 \%$ of disabled individuals exercised for at least $60 \mathrm{~min}$ three to four times a week, while only $3.9 \%$ did everyday. As few as $3.9 \%$ of the respondents practiced sport or were physically active less than an hour a day, three to four times a week, and only $1.9 \%$ everyday. Considering the disability levels, the WHO recommendations were met by $11.1 \%$ with mild, $11.1 \%$ with moderate, and $8.5 \%$ with severe disability.
The disabled Polish adults most often practiced sport for All on their own, i.e., at home - $62.5 \%$ and outdoors $-35.9 \%$. Only $7.7 \%$ of the respondents took part in organized classes at sport clubs or organizations for disabled individuals. The venues most often used for exercising were paid (20.5\%) and free (11.5\%) public facilities. Only $3.8 \%$ of the respondents exercised at private gyms or fitness clubs. There was no statistically significant difference in the disability level among the population.

Over $8 \%$ of the respondents reported that local authorities, sport clubs, and organizations organized various activities for disabled individuals in their residencies.

Similarly, we found a similar case in the evaluation of the activity of local authorities promoting physical activity (Table 4). None of these activity elements

Table 4. Activity of local authorities in the field of promoting physical activity, determining performance of health-enhanced physical activity of disabled Polish individuals $(n=155)$ and odds ratio and limits of $95 \%$ confidence interval

\begin{tabular}{|c|c|c|c|c|c|c|c|}
\hline \multirow[b]{2}{*}{$\begin{array}{l}\text { Activity of local authorities in the field of } \\
\text { promoting physical activity }\end{array}$} & \multicolumn{2}{|c|}{$\begin{array}{c}\text { Not meeting } \\
\text { WHO } \\
\text { recommendations }\end{array}$} & \multicolumn{2}{|c|}{$\begin{array}{c}\text { Meeting } \\
\text { WHO } \\
\text { recommendations }\end{array}$} & \multirow[b]{2}{*}{$p$} & \multirow[b]{2}{*}{ OR } & \multirow[b]{2}{*}{$95 \% \mathrm{CI}$} \\
\hline & $\mathrm{n}$ & $\%$ & $\mathrm{n}$ & $\%$ & & & \\
\hline \multicolumn{8}{|l|}{ Providing sufficient number of sports facilities } \\
\hline Yes & $60^{*}$ & 88.2 & 8 & 11.8 & \multirow{2}{*}{0.35} & 1 & - \\
\hline No & 56 & 91.8 & 5 & 8.2 & & 0.67 & $0.21-2.17$ \\
\hline \multicolumn{8}{|c|}{ Maintaining good condition of sports facilities } \\
\hline Yes & 88 & 90.7 & 9 & 9.3 & \multirow{2}{*}{0.17} & 1 & - \\
\hline No & 29 & 82.9 & 6 & 17.1 & & 2.02 & $0.66-6.17$ \\
\hline \multicolumn{8}{|l|}{ Organization of sport events } \\
\hline Yes & 84 & 87.5 & 12 & 12.5 & \multirow{2}{*}{0.55} & 1 & - \\
\hline No & 25 & 89.3 & 3 & 10.7 & & 0.84 & $0.22-3.21$ \\
\hline \multicolumn{8}{|l|}{ Promoting physical activity among citizens } \\
\hline Yes & 60 & 85.7 & 10 & 14.3 & \multirow[b]{2}{*}{0.44} & 1 & - \\
\hline No & 46 & 88.5 & 6 & 11.5 & & 0.78 & $0.27-2.31$ \\
\hline
\end{tabular}

WHO: World Health Organization; Odds ratios (OR) were calculated in relation to the ones not meeting WHO recommendations; CI: Confidence interval; The chi-square test was used; * The data do not total 155 due to responses "do not know/not sure". 
Table 5. Offer of clubs and sport organizations, determining performance of health-enhanced physical activity of disabled Polish individuals $(\mathrm{n}=155)$ and odds ratio and limits of $95 \%$ confidence interval

\begin{tabular}{|c|c|c|c|c|c|c|c|}
\hline \multirow[b]{2}{*}{ Offer of clubs and sport organizations } & \multicolumn{2}{|c|}{$\begin{array}{c}\text { Not meeting } \\
\text { WHO } \\
\text { recommendations }\end{array}$} & \multicolumn{2}{|c|}{$\begin{array}{c}\text { Meeting } \\
\text { WHO } \\
\text { recommendations }\end{array}$} & \multirow[b]{2}{*}{$p$} & \multirow[b]{2}{*}{ OR } & \multirow[b]{2}{*}{$95 \% \mathrm{CI}$} \\
\hline & $\mathrm{n}$ & $\%$ & $\mathrm{n}$ & $\%$ & & & \\
\hline \multicolumn{8}{|l|}{ Number of paid sports facilities } \\
\hline High & $32^{*}$ & 88.9 & 4 & 11.1 & \multirow{2}{*}{0.63} & 1 & - \\
\hline Low/none & 95 & 88.8 & 12 & 11.2 & & 1.01 & $0.3-3.36$ \\
\hline \multicolumn{8}{|l|}{ Number of free sports facilities } \\
\hline High & 45 & 93.8 & 3 & 6.3 & \multirow{2}{*}{0.27} & 1 & - \\
\hline Low/none & 84 & 86.6 & 13 & 13.4 & & 2.3 & $0.63-8.57$ \\
\hline \multicolumn{8}{|l|}{ Condition of paid sports facilities } \\
\hline Good & 80 & 87.0 & 12 & 13.0 & \multirow{2}{*}{0.35} & - & - \\
\hline Poor & 8 & 100.0 & - & - & & - & - \\
\hline \multicolumn{8}{|l|}{ Condition of free sports facilities } \\
\hline Good & 87 & 90.6 & 9 & 8.4 & \multirow{2}{*}{0.25} & 1 & - \\
\hline Poor & 17 & 81.0 & 4 & 19.0 & & 2.27 & $0.63-8.2$ \\
\hline \multicolumn{8}{|l|}{ Classes cost in paid public sports facilities } \\
\hline High & 30 & 85.7 & 5 & 14.3 & \multirow{2}{*}{0.51} & 1 & - \\
\hline Low & 11 & 91.7 & 1 & 8.3 & & 0.55 & $0.06-5.2$ \\
\hline \multicolumn{8}{|c|}{ Attractiveness of classes in paid public sports facilities } \\
\hline High & 29 & 85.3 & 5 & 14.7 & \multirow{2}{*}{0.49} & 1 & - \\
\hline Low & 43 & 87.8 & 6 & 12.2 & & 0.81 & $0.23-2.9$ \\
\hline
\end{tabular}

WHO: World Health Organization; Odds ratios (OR) were calculated in relation to the ones not meeting WHO recommendations; CI: Confidence interval; The chi-square test was used; * The data do not total 155 due to responses "do not know/not sure".

(caring over a sufficient number and condition of facilities, organization of sport events, or promotion of physical activity among citizens) were found to be determinants in fulfilling the WHO recommendations (Table 5).

\section{DISCUSSION}

The modern Polish model of support for disabled individuals assumes their physical activity. Disabled individuals are vulnerable to much higher health risks related with their sedentary lifestyle than individuals without disabilities. ${ }^{[37]}$ The cooperation between the formal social care system (medical - including physical therapy, educational, and economic), indirect support systems (non-governmental initiations), family, selfsupport groups, and volunteers ${ }^{[27]}$ can lead to increased levels of their physical activity and, as a result, to decreased secondary changes, ${ }^{[38]}$ improved health and fitness, a better functioning life, and improved quality of life. ${ }^{[14]}$

The studies on Poles have shown that these activities are indispensable. According to the European Union (EU) estimates, the number of disabled individuals in Poland (in the population and at working age) was the highest among member states as $16 \%{ }^{[39]}$ More interestingly, the disabled Polish individuals most often evaluate their fitness as very poor $(36.5 \%)$ or poor $(31.1 \%)^{[40]}$ and functional efficiency as low. ${ }^{[41]}$ As many as $25.8 \%$ of them undertake no physical activity. Only $10.1 \%$ of them regularly do sports or physical recreation. ${ }^{[40]}$ These findings indicate two problems. On one hand, they confirm this alarming phenomenon, as (on the basis on the survey concerning participation in Sport for All the active fraction (meeting WHO standards) is only $10.3 \%$. At the same time, the US Physical Activity Guidelines Advisory Committee convened by the U.S. Department of Health and Human Services recommends as follows: ${ }^{[42]}$

- Adults with disabilities should strive to get at least $150 \mathrm{~min}$ a week of moderate intensity or 75 min a week of vigorous-intensity, aerobic activity, or an equivalent combination of moderate- and vigorous-intensity aerobic activity. Aerobic activity should be performed in episodes of at least $10 \mathrm{~min}$, and preferably, it should be spread throughout the week.

- Adults with disabilities, who are able to, should also do muscle-strengthening activities of moderate or high intensity that involve all major muscle groups on two or more days a week. These activities provide additional health benefits. 
- When adults with disabilities are not able to meet these guidelines, they should engage in regular physical activity according to their abilities and should avoid inactivity.

Adults with disabilities should consult their health care provider about the amounts and types of physical activity that are appropriate for their abilities.

On the other hand, the Polish results indicate methodology problems related with implementation of the IPAQ-LF. According to reports of the respondents, as many as $68.2 \%$ of the respondents performed a recommended dose of physical activity ( $>600 \mathrm{MET}$ $\mathrm{min} /$ week) in their leisure time. This seems improbable, particularly, compared to the other reports. An Irish study ${ }^{[43]}$ in which physical activity was classified in a way similar to the Polish classification (intensive/ strenuous meant sweating, out of breath, heart beating faster, moderate - a little out of breath but heart not beating faster, mild/low - minimal effort such as gentle walking), the $\mathrm{WHO}$ recommendations were met only by $18 \%$ of individuals with mental disability and $11 \%$ with physical disability. In the case of physically disabled individuals, low physical activity characterized $44 \%$ of them, moderate - $18 \%$ and intensive only $4 \%$. In the case of individuals with mental disabilities, the rates were as follows: $9 \%, 40 \%$, and $15 \%$. The recognition of the results of the survey on participation in the sport for all is more realistic. The results confirm our hypothesis which suggests that physical activity of the disabled individuals is too low to meet the WHO standards. This is all the more important, as the analysis of the presented data also disputes the high activity of disabled individuals. A distribution of the frequency of efforts classifying them to a level of physical activity sufficient to meeting WHO norms shows that total leisure activity mainly comprises vigorous activities (58.8\%; $\geq 75 \mathrm{~min} /$ week). However, moderate activity ( $\geq 150 \mathrm{~min} /$ week) was reported by only $11.8 \%$ and walking ( $\geq 150 \mathrm{~min} /$ week) - only $7.2 \%$. This finding indicates an often-recorded problem of results classification. ${ }^{[43]}$

Due to these doubts - for further analyses respondents were classified (active/inactive) not on the basis of the IPAQ-LF but their physical activity (number of day and min) reported in the study. Unfortunately, the results do not confirm our another hypothesis suggesting that there is a positive relationship between the activities of local authorities, clubs and sports organization and health-enhanced physical activity of disabled Polish individuals. In addition, these results showed that none of the variables (offer, promotional activity of local authorities, clubs, and sport organizations) were associated with the physical activity of the disabled Polish adults. This seems interesting, as most authors present the activity of local governments as a significant factor in increasing the level of physical activity of disabled individuals. ${ }^{[44]}$ In Boland's study ${ }^{[43]}$ including the East Coast of the US disabled individuals who lived in the residential settings were more likely to reach recommended activity levels. The author claimed that this could be due to the fact that the staff in these residential settings motivated clients to exercise. Mitchell and Sloper ${ }^{[45]}$ also proved that a lack of access to recreation and integrating activities led children with disabilities to being bored and lonely. In turn, these children tended to sit and watch TV. ${ }^{[46]}$ The Local Sports Partnership in Sligo and Donegal with the North Western Health Board ${ }^{[43]}$ suggested that the reason that more than half the disabled individuals exercised two to three times a week using the services provided for them. On the other hand, Rimmer ${ }^{[12]}$ claimed that fewer than $10 \%$ of Afro-American women with disabilities participated in organized physical activity programs. There is a consensus in the EU (54\%) that local authorities undertake sufficient activities enabling citizens performing physical activity (35\% believe opposite; they do not do everything that they can do). ${ }^{[47]}$

However, several studies in Poland have demonstrated that local authorities, clubs, and sport organizations organize activities for only over $8 \%$ of disabled individuals. Mobilizing Polish adults with disabilities to manage their health on their own requires more attention. Wider promotion of physical activity, the full support of service providers and local governments, and improved programs can increase their awareness of the advantages of physical activity and the ability to undertake it. This seems to be the greatest problem of Polish adults with disabilities. A low awareness of both the importance of exercise and the effects of health on health, as well as a lack of motivation, are most often the reasons why disabled individuals do not lead active lives. ${ }^{[7]}$ It may also be caused by insufficient knowledge about physical activity guidelines among the disabled as well as representatives of the local government. However, the awareness itself, without the support, orientation, and modeling of activity from authorities and local organization is not enough for leading an acting life. ${ }^{[48]}$

Why was there no relationship between healthy behaviors of disabled individuals and the health promotion campaigns developed by local authorities? 
The US experience points to the limited knowledge by health care providers who should be screening to assure a high enough activity level is achieved. Likely, this is the case in Poland. It seems that well-managed campaigns leave stronger results in the memories of individuals who exercise. They form a specific opinion about advantages of this activity. Perhaps reasons for the lack of such relation are that disabled Polish individuals rarely undertake physical activity and they are not able to clearly specify the level of the local government support.

Furthermore, promoting physical activity of disabled individuals is a new field, both at the level of organization, as well as the implementation. Difficulties which disabled individuals face are greater than typical barriers experienced by those without disabilities practicing sport or recreation. Unfriendly and negative attitudes can form barriers that are insurmountable for numerous disabled individuals. ${ }^{[49]}$ Thus, there is an increased need for effective strategies for improving and maintaining both the functions and the quality of life of these individuals. Their participation in physical activity needs to become one of the highest priorities for public and private organizations responsible for the improvement of health of each citizen.

One of the limitations is the subjective classification of physical activity intensity. Often enough, there was noted the fact, particularly in case of the elderly, ${ }^{[50]}$ that it is more difficult to recall moderate efforts than vigorous ones. Another significant problem is also a belief often held by respondents that the activity they undertake is highly intensive. ${ }^{[51]}$ This is highly probable for disabled individuals and is particularly important due to the fact that MET value has the greatest influence on the final evaluation of the physical activity level. What is more, in the Polish version of the IPAQ-LF, the terms "vigorous physical activity" and "moderate physical activity" were replaced by "vigorous physical effort" and "moderate physical effort", respectively, as both terms are defined by the pace of breathing and heartbeat. ${ }^{[34]}$ An average Polish respondent may associate faster breath and heartbeat with effort more than physical activity; however, it may not be so evident for disabled individuals. They may associate intensive effort with everyday problems. This makes us rethink the use of this tool for disabled Polish individuals.

In addition, it must be noted that the study is based on the representative sample of the Polish population, not a representative sample of Poles with disability.
Therefore, one must be attentive in generalizing the results to the overall population of disabled individuals.

In conclusion, there is a need to increase the activity of local authorities and governments in promoting participation in sport for all among disabled Polish individuals. Each organization serving this aim (i.e., organizing advantageous and satisfying forms, special educational programs, and specialized sport and recreation centers) may become an important channel activating disabled Polish individuals in this field.

\section{Acknowledgment}

The project was funded by Department of Analysis and Sport Policy of the Ministry of Sport and Tourism of the Republic of Poland.

\section{Declaration of conflicting interests}

The authors declared no conflicts of interest with respect to the authorship and/or publication of this article.

\section{Funding}

The authors received no financial support for the research and/or authorship of this article.

\section{REFERENCES}

1. Act of 27 August 1997 on Vocational and Social Rehabilitation and Employment of Persons with Disabilities. Dziennik Ustaw 1997;123:3735-49.

2. Data of the Labour Force Survey (LFS). Available from: http://www.stat.gov.pl. Badania Aktywności Ekonomicznej Ludności (BAEL)-in Polish. [Access: February 02, 2015].

3. National Census of Population and Housing. Available from: http://www.stat.gov.pl [Access: February 02, 2015].

4. Turk MA. Secondary conditions and disability. In: Field MJ, Jette AM, Martin L, editors. Workshop on disability in America. Washington DC: National Academies Press; 2006. p. 185-93.

5. Jones GC, Sinclair LB. Multiple health disparities among minority adults with mobility limitations: san application of the ICF framework and codes. Disabil Rehabil 2008;30:901-15.

6. Jones GC, Bell K. Adverse health behaviors and chronic conditions in working-age women with disabilities. Fam Community Health 2004;27:22-36.

7. Centers for Disease Control and Prevention (CDC). Physical activity among adults with a disability--United States, 2005. MMWR Morb Mortal Wkly Rep 2007;56:1021-4.

8. Krahn GL, Hammond L, Turner A. A cascade of disparities: health and health care access for people with intellectual disabilities. Ment Retard Dev Disabil Res Rev 2006;12:70-82.

9. Rimmer JH, Shenoy SS. Impact of exercise on targeted secondary conditions In: Field MJ, Jette AM, Martin L, editors. Workshop on disability in America. Washington, DC: The National Academies Press; 2006. p. 205-21.

10. Drum CE, Krahn GL, Culley C, Hammond L. Recognizing and responding to the health disparities of people with disabilities. California Journal of Health Promotion 2005;3:29-42. 
11. Centers for Disease Control disability and health state chartbook: profiles of health for adults with disabilities. Atlanta, GA: US Department of Health and Human Services; 2006

12. Rimmer JH. Health promotion for people with disabilities: the emerging paradigm shift from disability prevention to prevention of secondary conditions. Phys Ther 1999;79:495-502.

13. Abdullah N, Horner-Johnson W, Drum CE, Krahn GL, Staples E, Weisser J, et al. Healthy lifestyles for people with disabilities. Calif J of Health Promot 2004;2:42-54.

14. US Department of Health and Human Services. The 2005 Surgeon General's Call to Action to Improve the Health and Wellness of Persons with Disabilities. Washington DC: Office of the Surgeon General; 2005.

15. Harrison T. Health promotion for persons with disabilities: what does the literature reveal? Fam Community Health 2006;29:12-9.

16. Rimmer JH, Yamaki K. Obesity and intellectual disability. Ment Retard Dev Disabil Res Rev 2006;12:22-7.

17. Centers for Disease Control and Prevention (CDC). State-specific prevalence of obesity among adults with disabilities--eight states and the District of Columbia, 19981999. MMWR Morb Mortal Wkly Rep 2002;51:805-8.

18. Fernhall B, Unnithan VB. Physical activity, metabolic issues, and assessment. Phys Med Rehabil Clin N Am 2002;13:925-47.

19. McDonald CM. Physical activity, health impairments, and disability in neuromuscular disease. Am J Phys Med Rehabil 2002;81:108-20.

20. Steele CA, Kalnins IV, Rossen BE, Biggar DW, Bortolussi JA, Jutai JW. Age-related health risk behaviors of adolescents with physical disabilities. Soz Praventivmed 2004;49:132-41.

21. Grunbaum JA, Kann L, Kinchen SA, Williams B, Ross JG, Lowry R, et al. Youth risk behavior surveillance--United States, 2001. MMWR Surveill Summ 2002;51:1-62.

22. Sallis JF, Glanz K. The role of built environments in physical activity, eating, and obesity in childhood.Future Child 2006;16:89-108.

23. Liou TH, Pi-Sunyer FX, Laferrère B. Physical disability and obesity. Nutr Rev 2005;63:321-31.

24. Foxhall K. Beginning to begin: reports from the battle on obesity. Am J Public Health 2006;96:2106-12.

25. US Department of Education. Twenty-Fifth Annual Report to Congress on the Implementation of the Individuals with Disabilities Education Act: Office of Special Education and Rehabilitative Services; 2005.

26. Levins SM, Redenbach DM, Dyck I. Individual and societal influences on participation in physical activity following spinal cord injury: a qualitative study. Phys Ther 2004;84:496-509.

27. Rimmer JH. The conspicuous absence of people with disabilities in public fitness and recreation facilities: lack of interest or lack of access? Am J Health Promot 2005;19:327-9.

28. Kerstin W, Gabriele B, Richard L. What promotes physical activity after spinal cord injury? An interview study from a patient perspective. Disabil Rehabil 2006;28:481-8.
29. Rimmer JH, Wang E, Smith D. Barriers associated with exercise and community access for individuals with stroke. J Rehabil Res Dev 2008;45:315-22.

30. Scelza WM, Kalpakjian CZ, Zemper ED, Tate DG. Perceived barriers to exercise in people with spinal cord injury. Am J Phys Med Rehabil 2005;84:576-83.

31. Rimmer JH Building inclusive physical activity communities for people with vision loss. J Vis Impair Blind 2006;100:863-5.

32. Rimmer JH. Use of the ICF in identifying factors that impact participation in physical activity/rehabilitation among people with disabilities. Disabil Rehabil 2006;28:1087-95.

33. Rimmer J, Chen M. A systematic review of health outcomes associated with physical activity in people with disabilities. Presented at the 2008 American Public Health Association Annual Meeting; San Diego; 2008.

34. Biernat E. International Physical Activity QuestionnairePolish long version. Polish Journal of Sports Medicine 2013;29:1-15

35. Craig CL, Marshall AL, Sjöström M, Bauman AE, Booth $\mathrm{ML}$, Ainsworth $\mathrm{BE}$, et al. International physical activity questionnaire: 12-country reliability and validity. Med Sci Sports Exerc 2003;35:1381-95.

36. Guidelines for Data Processing and Analysis of the International Physical Activity Questionnaire (IPAQ)-Short and Long Forms; 2005. Available from: http://www.ipaq.ki.se [Access: December 22, 2014].

37. Weil E, Wachterman M, McCarthy EP, Davis RB, O'Day B, Iezzoni LI, et al. Obesity among adults with disabling conditions. JAMA 2002;288:1265-8.

38. Nosek MA, Hughes RB, Petersen NJ, Taylor HB, Robinson-Whelen S, Byrne M, et al. Secondary conditions in a community-based sample of women with physical disabilities over a 1-year period. Arch Phys Med Rehabil 2006;87:320-7.

39. Wilmowska A, Goryński P. Niepełnosprawność rejestrowana w systemie ubezpieczenia społecznego. In: Wojtyniak B, Goryński P, editors. Sytuacja zdrowotna ludności Polski. Narodowy Instytut Zdrowia Publicznego-Państwowy Zakład Higieny Warszawa: 2008. p. 171-7.

40. Participation of Poles in sports and physical recreation in 2012. Warsaw: Central Statistical Office; 2013.

41. Kurkus-Rozowska B. The influence of rehabilitation on physical work capacity of people with disabilities. Bezpieczeństwo Pracy: Nauka i praktyka 2002;3:20-5.

42. The Physical Activity Guidelines for Adults with Disabilities. In 2008 Physical Activity Guidelines for Americans. The U.S. Physical Activity Guidelines Advisory Committee. Available from http://www.health. gov/paguidelines/guidelines/chapter7.aspx [Access: February 24, 2015].

43. Hannon F. Promoting the Participation of People with Disabilities in Physical Activity and Sport in Ireland. Disability Research Series 2005:1-149. Available from: http://www.nda.ie/cntmgmtnew.nsf/0/7020D28F7F65773A 802570F30057F05E/\$File/Promoting_Participation_Sport. pdf [Access: February 12, 2015]. 
44. Longmuir PE, Bar-Or O. Factors influencing the physical activity levels of youths with physical and sensory disabilities. APAQ 2000;17(1):40-53.

45. Mitchell W, Sloper P. Quality in services for disabled children and their families: What can theory, practice and research in children's and parents' views tell us? Children \& Society 2001;15:237-52.

46. Mulderij KJ. Research into the lifeworld of physically disabled children. Child Care Health Dev 1996;22:311-22.

47. Special Eurobarometer 334 / Wave 72.3. TNS Opinion \& Social: Sport and Physical Activity. Brussels: March 2010.

48. Baranowski J. Aktywność fizyczna niepełnosprawnych intelektualnie stopnia lekkiego /Physical activity of persons with light disability level/. Zeszyty Metodyczno-Naukowe Wydawnictwo AWF w Katowicach 2006;21:7-16.

49. Heller T, Hsieh K, Rimmer J. Barriers and supports for exercise participation among adults with Down syndrome, Journal of Gerontological Social Work 2002;38:161-78.

50. Rzewnicki R, Vanden Auweele Y, De Bourdeaudhuij I. Addressing overreporting on the International Physical Activity Questionnaire (IPAQ) telephone survey with a population sample. Public Health Nutr 2003;6:299-305.

51. Biernat E, Stupnicki R, Lebiedziński B, Janczewska L. Assessment of physical activity by IPAQ questionnaire. Phys Edu Sport 2008;52:83-9. 